\title{
Pharmacological interventions for people with depression and chronic physical health problems: systematic review and meta-analyses of safety and efficacy
}

\author{
David Taylor, Nicholas Meader, Victoria Bird, Steve Pilling, Francis Creed and David Goldberg, \\ on behalf of the pharmacology subgroup of the National Institute for Health and Clinical Excellence \\ Guideline Development Group for Depression in Chronic Physical Health Problems
}

\section{Background}

Antidepressant drugs are widely used in the treatment of depression in people with chronic physical health problems.

\section{Aims}

To examine evidence related to efficacy, tolerability and safety of antidepressants for people with depression and with chronic physical health problems.

\section{Method}

Meta-analyses of randomised controlled efficacy trials of antidepressants in depression in chronic physical health conditions. Systematic review of safety studies.

\section{Results}

Sixty-three studies met inclusion criteria (5794 participants). In placebo-controlled studies, antidepressants showed a significant advantage in respect to remission and/or response: selective serotonin reuptake inhibitors (SSRIS) risk ratio $(\mathrm{RR})=0.81(95 \% \mathrm{Cl} 0.73-0.91)$ for remission, $\mathrm{RR}=0.83$ $(95 \% \mathrm{Cl} 0.71-0.97)$ for response; tricyclics RR $=0.70(95 \% \mathrm{Cl}$ 0.40-1.25 (not significant)) for remission, $\mathrm{RR}=0.55$ (95\% 0.430.70 ) for response. Both groups of drugs were less well tolerated than placebo (leaving study early due to adverse effects) for SSRIS RR $=1.80$ (95\% Cl 1.16-2.78), for tricyclics $\mathrm{RR}=2.00$ (95\% Cl 0.99-3.57). Only SSRIS were shown to improve quality of life. Direct comparisons of SSRIS and tricyclics revealed no advantage for either group for remission, response, effect size or tolerability. Effectiveness studies suggest a neutral or beneficial effect on mortality for antidepressants in participants with recent myocardial infarction.

\section{Conclusions}

Antidepressants are efficacious and safe in the treatment of depression occurring in the context of chronic physical health problems. The SSRIs are probably the antidepressants of first choice given their demonstrable effect on quality of life and their apparent safety in cardiovascular disease.

\section{Declaration of interest}

D.T. has received consultancies fees, lecturing honoraria and/or research funding from AstraZeneca, Janssen-Cilag, Servier, Sanofi-Aventis, Lundbeck, Bristol-Myers Squibb, Novartis, Eli Lilly and Wyeth. F.C. has received honoraria from Eli Lilly for speaking at scientific meetings.
Depression shows a strong association with numerous chronic physical conditions, ${ }^{1-6}$ including diabetes, arthritis, multiple sclerosis, congestive heart failure, hypertension, coronary artery disease, chronic obstructive pulmonary disease and end-stage renal disease. There are further associations with non-specific syndromes such as obesity, ${ }^{7}$ chronic fatigue syndrome and fibromyalgia. ${ }^{6}$ The coexistence of depression and chronic physical conditions predicts significantly worsened health status $^{8}$ and functional disability. ${ }^{2}$ Depression is considered by some to be a modifiable risk factor for morbidity and mortality in conditions such as diabetes ${ }^{9-11}$ and cardiovascular disease. ${ }^{12-14}$ In addition, suicide may be relatively more common in those with certain chronic physical illnesses. ${ }^{15,16}$ Individuals with depression are three times less likely to adhere to medical treatment than individuals without depression. ${ }^{17}$

Effective treatment of depression might therefore be expected to improve functional disability and health-related quality of life for people with depression and chronic physical health problems. Even if these predicted benefits are discounted, the effective treatment of depression in chronic physical illness can be considered no less desirable than the effective treatment of depression in the absence of physical health problems. In the clinical care of this population, however, depression is often not recognised and diagnosed. When it is recognised, some clinicians may be reluctant to prescribe antidepressants in physical illness because of concerns about adverse physical effects or drug interactions. Our aim was to systematically appraise the effects of treating depression with pharmacological treatment in adults with chronic medical conditions and to calculate their effect size and assess their effect on remission rates and quality of life.

In 2009, the UK National Institute for Health and Clinical Excellence (NICE) produced evidence-based guidelines on the treatment of depression in chronic physical health problems. ${ }^{18}$ As part of this process, we conducted a systematic review of the efficacy and safety of antidepressant medication in depression in the context of chronic physical conditions.

\section{Method}

\section{Search strategy and inclusion criteria}

The full review protocol has been published in the guideline on depression in chronic physical health problems, which was commissioned by NICE. ${ }^{18}$ Briefly, a search was conducted for randomised controlled trials (RCTs) involving the comparison of selective serotonin reuptake inhibitors (SSRIs), tricyclic antidepressants (TCAs), venlafaxine, duloxetine, mirtazapine, mianserin, trazodone (and other named antidepressants licensed since 1958) with placebo or other antidepressants in participants with depression and a chronic physical illness using five electronic 
bibliographic databases (CENTRAL, CINAHL, EMBASE, MEDLINE, PsycINFO).

A priori defined chronic physical health problems included asthma, cancer, cardiovascular disease, chronic obstructive pulmonary disease, diabetes, end-stage renal disease, epilepsy, general medical illness, HIV disease, multiple sclerosis, Parkinson's disease, rheumatoid arthritis and stroke. Participants with a range of (sometimes unspecified) chronic physical conditions recruited from general medical wards or receiving home healthcare for chronic conditions were grouped under general medical illness for the purposes of this analysis. Depression was defined as a DSM or ICD diagnosis of depression or identified as scoring positive for depression according to a validated depression scale.

Included outcomes were remission, response, discontinuation for any reason, discontinuation due to adverse events, mean score on a validated depression scale, mean score on quality of life measure and physical health outcomes.

Extensive search terms for depression and RCTs were used with no limitations set for interventions, outcomes, or physical health conditions in order to maximise sensitivity of the search (see the online supplement for details of the search strategy used for MEDLINE, EMBASE, CINAHL and PsycINFO). The search was part of a larger search for evidence relevant to the depression and chronic physical health problem guideline. Each database was searched from inception to March 2009. Additional papers were found by searching the references of retrieved articles, tables of contents of relevant journals, previous systematic reviews and meta-analyses of depression and chronic physical health problems, written requests to experts and suggestions made by the members of the Guideline Development Group. The search was repeated in December 2009.

\section{Quality assessment}

All studies that met the eligibility criteria above were assessed for methodological quality using the Scottish Intercollegiate Guidelines Network (SIGN) checklist for RCTs (includes items on method of randomisation, allocation concealment, masking, completion of treatment and differences between groups other than treatment). ${ }^{19}$ Studies that were not clearly described as randomised were excluded from the efficacy review. Effectiveness trials were included in the safety review if they included a sample size greater than 200 and had a control group. We created GRADE profiles and classified the overall quality of the evidence (high, moderate, low, very low) using the GRADE system, ${ }^{20}$ which takes into account quality assessment of individual studies (as examined in the SIGN checklist discussed above), the consistency of the results (consistency indicated by $I^{2}$ less than 50\% were downgraded) and the directness (whether or not participants were sufficiently applicable to the target population of the review, see above) of the evidence.

\section{Data extraction}

The assessment of study quality and outcome data extraction were completed by one systematic reviewer and double-checked by a second for accuracy, with disagreements resolved by discussion. Where available, data were extracted for the following efficacy outcomes: mean depression scale score (both clinician-rated and patient-rated scales were extracted where available. For studies reporting more than one scale, Hamilton Rating Scale for Depression (HRSD) $)^{21}$ was extracted in favour of other clinicianrated scales. Similarly, the Beck Depression Inventory (BDI) ${ }^{22}$ was favoured over other self-report measures); response (e.g. proportion of participants experiencing a 50\% improvement in depression score); remission (no longer meeting the cut-off for depression diagnosis on a depression scale); quality of life (e.g. Short Form-36 (SF-36)); ${ }^{23}$ and physical health symptoms. With regard to safety and tolerability, the main outcome measure assessed was withdrawals from trials due to adverse effects. We also recorded and compared numbers of participants leaving studies early for any reason.

\section{Statistical analysis}

Meta-analysis was used, where appropriate, to synthesise the evidence using Review Manager 5 software for Windows. ${ }^{24}$ Intention-to-treat with last-observation-carried-forward (LOCF) was favoured over observed case (although it was recognised that the LOCF may introduce an unknown level of bias). For consistency of presentation, all continuous data were entered into Review Manager in such a way that negative effect sizes represented an effect that favoured the active drug. The standardised mean difference (SMD) or effect size was calculated from continuous data and the risk ratio (RR) was calculated from binary data. Data from more than one study were pooled using a random-effects model. Publication bias was assessed by visually inspecting the symmetry of funnel plots and, formally, using Egger's test. ${ }^{25}$

\section{Results}

We found 63 studies meeting inclusion criteria (Fig. 1 and online Table DS1). There was no evidence of publication bias as assessed by funnel plots and Egger's test for all comparisons.

\section{SSRIS $V$. placebo}

A total of 35 RCTs compared SSRIs with placebo for people with depression and chronic physical health problems. ${ }^{26-60}$ (One of these reports ${ }^{42}$ was treated as three separate trials by abstracting data from an a priori secondary analysis ${ }^{61}$ that grouped participants according to the number of chronic physical illnesses from which they suffered.) All but three $e^{29,45,53}$ were double-blind trials. Seven studies examined the treatment of depression in

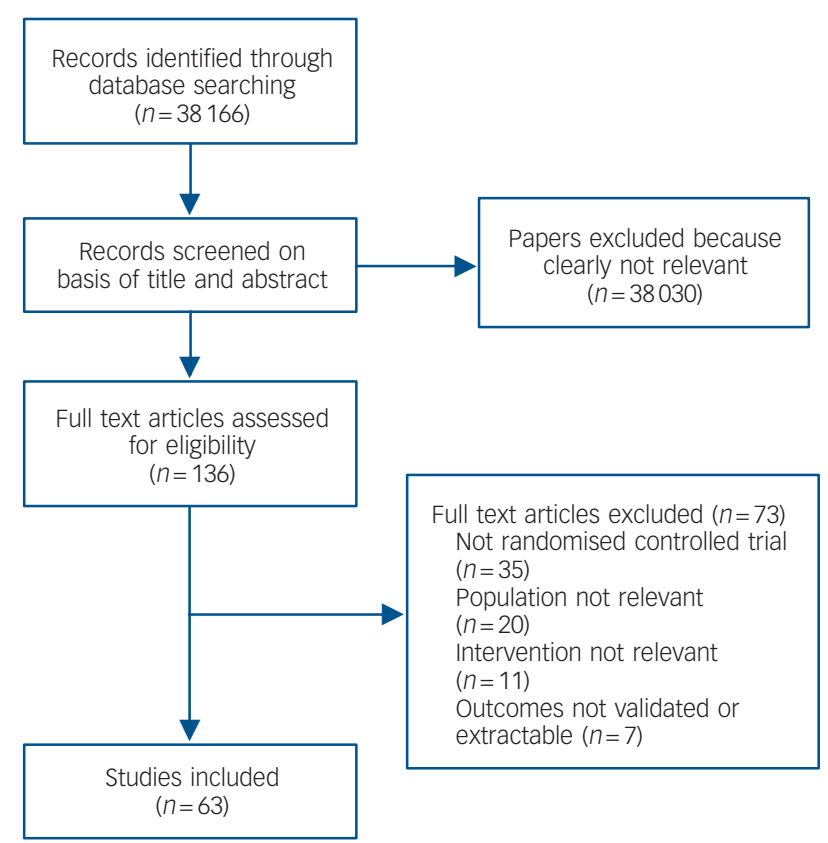

Fig. 1 Study flow diagram for efficacy studies 


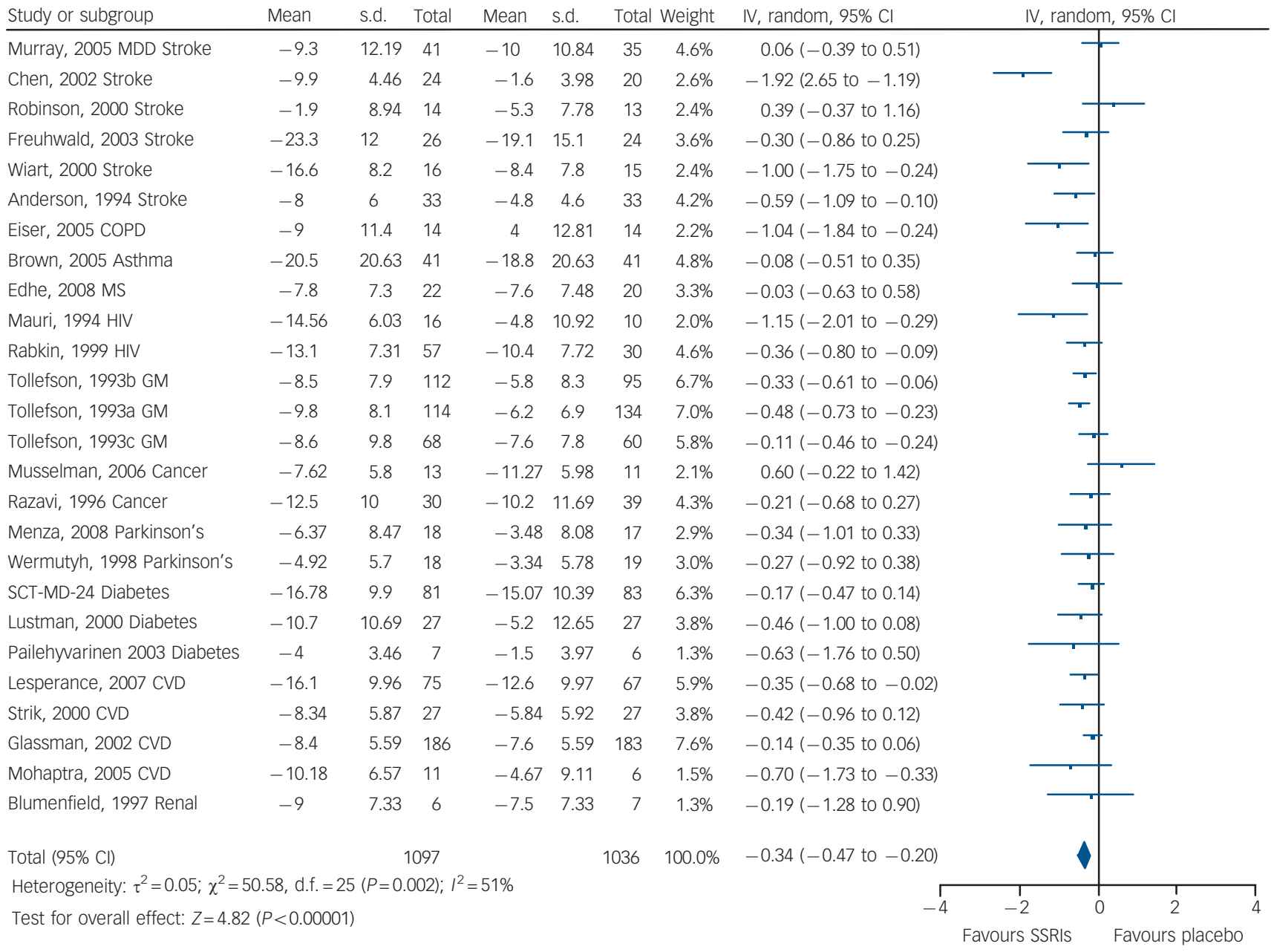

Fig. 2 Selective serotonin reuptake inhibitors (SSRIS) v. placebo: mean change in observer-rated depression rating scale score.

stroke, five in diabetes, four each in cardiovascular disease, cancer, Parkinson's disease and general medical illness, three in HIV, two in chronic obstructive pulmonary disease and one in asthma, renal disease and multiple sclerosis.

There was consistent evidence that SSRIs had a small-tomedium benefit on depression outcomes in comparison with placebo whether the analysis considered all studies or was confined to double-blind studies only (Fig. 2). The SSRIs were associated with higher levels of remission and response when compared with placebo (Table 1). Remission: (all studies: $\mathrm{RR}=0.81$, 95\% CI $0.73-0.91$; double blind only: $\mathrm{RR}=0.88$, 95\% CI 0.81-0.95), response: (all studies: $\mathrm{RR}=0.83,95 \% \mathrm{CI}$ 0.71-0.97; double blind only: $\mathrm{RR}=0.89,95 \%$ CI $0.81-0.98$ ).

A robust positive effect was also found for mean change in depression rating scale score (effect size), although there were differences in the size of the effect depending on whether patient-rated or observer-rated scales were used. Patient-rated scales (all studies: $\mathrm{SMD}=-0.19,95 \% \mathrm{CI}-0.36$ to -0.02 ; double blind only: SMD $=-0.20,95 \%$ CI -0.38 to -0.02 ). Observerrated scales (all studies: $\mathrm{SMD}=-0.34,95 \% \mathrm{CI}-0.48$ to -0.20 ; double blind only: $\mathrm{SMD}=-0.28,95 \% \mathrm{CI}-0.39$ to -0.17) (Table 1 and Fig. 2).

There were mixed data concerning tolerability of SSRIs. No differences were found compared with placebo for leaving the study for any reason $(\mathrm{RR}=1.13,95 \%$ CI 0.97-1.32). However, participants receiving SSRIs were more likely to leave the study early because of adverse events ( $\mathrm{RR}=1.80,95 \%$ CI 1.16-2.78).

There were fewer data on health-related quality of life and physical health outcomes. Where these were reported, measures differed substantially between studies. In total there were seven studies that provided data on quality of life, indicating a small benefit in favour of SSRIs (SMD $=-0.27,95 \%$ CI -0.44 to $-0.10)$. There were five studies reporting the physical subscale of the SF- $36^{23}$ that showed no difference between groups $(\mathrm{SMD}=0.02,95 \% \mathrm{CI}-0.19$ to 0.23 ).

It was not possible or appropriate to pool data on physical health outcomes because of differences between physical health conditions in which outcomes were examined, but also because of varied reporting of outcomes.

\section{TCAs v. placebo}

We found nine double-blind RCTs that compared TCAs with placebo, ${ }^{30,62-69}$ mostly conducted in the 1980s and 1990s. Three of these studies examined the effect of TCAs in depression occurring in the context of stroke, two in general medical illness and one each in Parkinson's disease, chronic obstructive pulmonary disease, diabetes and HIV. 
Table 1 Evidence summary of selective serotonin reuptake inhibitors $v$. placebo

\begin{tabular}{|c|c|c|c|c|c|}
\hline \multirow[b]{2}{*}{ Outcomes } & \multirow{2}{*}{$\begin{array}{c}\text { Participants (studies), } \\
n\end{array}$} & \multirow{2}{*}{$\begin{array}{l}\text { Quality of the } \\
\text { evidence, GRADE }\end{array}$} & \multicolumn{2}{|c|}{ Effect size } & \multirow[b]{2}{*}{$95 \% \mathrm{Cl}$} \\
\hline & & & SMD & $\mathrm{RR}$ & \\
\hline \multicolumn{6}{|l|}{ Depression } \\
\hline \multicolumn{6}{|l|}{ Continuous measures } \\
\hline Patient rated & $923(12)$ & Moderate $^{a}$ & -0.19 & & -0.36 to -0.02 \\
\hline Observer rated & $2133(26)$ & Low $^{a, c}$ & -0.34 & & -0.47 to -0.20 \\
\hline \multicolumn{6}{|l|}{ Not achieving success/remission } \\
\hline Observer rated & $1197(14)$ & Moderate $^{a}$ & & 0.81 & 0.73 to 0.91 \\
\hline Patient rated & $60(1)$ & Moderate $^{d}$ & & 0.74 & 0.46 to 1.18 \\
\hline \multicolumn{6}{|l|}{ Non-response } \\
\hline Patient rated & $279(3)$ & $\operatorname{Low}^{\mathrm{b}, \mathrm{c}}$ & & 0.73 & 0.44 to 1.22 \\
\hline Observer rated & $1267(19)$ & $\operatorname{Low}^{\mathrm{a}, \mathrm{c}}$ & & 0.83 & 0.71 to 0.97 \\
\hline QoL: continuous measures, e.g. SQOLI, FACT-G & $524(7)$ & Moderate $^{a}$ & -0.27 & & -0.44 to -0.1 \\
\hline $\begin{array}{l}\text { Physical outcome/QoL - General physical functioning/well-being } \\
\text { (SF-36 physical component) }\end{array}$ & $338(5)$ & Moderate $^{b}$ & 0.02 & & -0.19 to 0.23 \\
\hline \multicolumn{6}{|l|}{ Leaving the study early } \\
\hline Any reason & $3137(25)$ & Moderate $^{a}$ & & 1.13 & 0.97 to 1.32 \\
\hline As a result of adverse events & $1661(13)$ & Moderate $^{a}$ & & 1.80 & 1.16 to 2.78 \\
\hline \multicolumn{6}{|c|}{$\begin{array}{l}\text { SMD, standardised mean difference; RR, risk ratio; QoL, quality of life; SQOLI, Splitzer Quality of Life Index; FACT-G, Functional Assessment of Cancer Therapy - General; SF-36, } \\
\text { Short Form-36. } \\
\text { a. Some studies did not clearly report whether double blind. } \\
\text { b. } 95 \% \text { Cl compatible with benefit and no benefit. } \\
\text { c. } I^{2}>50 \% \text {. } \\
\text { d. Sparse data. }\end{array}$} \\
\hline
\end{tabular}

There was evidence of medium-to-large benefits on most depression outcomes (Table 2 and Fig. 3). Participants receiving TCAs were more likely to respond to treatment ( $R R=0.55,95 \%$ CI $0.43-0.70)$. There was no statistically significant effect on remission ( $\mathrm{RR}=0.70,95 \%$ CI $0.40-1.25$ ) (two studies reported this outcome). Mean differences on observer-rated depression scales were of a medium-to-large magnitude $(\mathrm{SMD}=-0.70$, $95 \%$ CI -0.97 to -0.43 ) (Fig. 3). Similar effects were found on patient-rated scales ( $\mathrm{SMD}=-0.58,95 \% \mathrm{CI}-1.14$ to -0.02 ).

There was evidence of a trend for TCAs being less well tolerated compared with placebo (Table 2). People on TCAs were not significantly more likely to leave the study for any reason (6 studies, 302 participants) ( $\mathrm{RR}=1.23,95 \% \mathrm{CI} 0.81-1.88)$, but were numerically more likely to leave because of adverse events (5 studies, 239 participants) $(\mathrm{RR}=1.88,95 \%$ CI $0.99-3.57)$.

There were very limited data on quality of life and physical health outcomes and so a meta-analysis of these outcomes was not undertaken.

\section{Other drugs $v$. placebo}

There was one study of trazodone ${ }^{70}$ in post-stroke depression that indicated large benefits in comparison with placebo for mean depression rating scale score $(\mathrm{SMD}=-1.03,95 \% \mathrm{CI}-1.93$ to $-0.13)$. This study was not double blind. There was one double-blind study of mirtazapine in depression after myocardial infarction. ${ }^{71}$ Participants in the mirtazapine group were less likely to leave the study for any reason compared with placebo $(\mathrm{RR}=0.57,95 \%$ CI $0.35-0.94)$. There were small suggested benefits in favour of mirtazapine in terms of remission $(0.87$, $95 \%$ CI 0.63 to 1.21$)$, response $(0.83,95 \%$ CI 0.58 to 1.20$)$ and effect size ( $\mathrm{SMD}=-0.21,95 \% \mathrm{CI}-0.62$ to 0.20 ), but none of these effects was statistically significant. Wise and colleagues ${ }^{72}$ conducted a double-blind trial on duloxetine in elderly individuals with medical comorbidities that was found to be associated with a small-to-medium benefit in terms of mean difference on depression scale score (patient-rated: $\mathrm{SMD}=-0.37,95 \% \mathrm{CI}-0.67$ to -0.14 ; observer-rated: $\mathrm{SMD}=-0.43,95 \% \mathrm{CI}-0.71$ to -0.16 ).

Two studies examined mianserin $v$. placebo ${ }^{73,74}$ (both double blind), which suggested strong benefits favouring mianserin on leaving the study for any reason $(\mathrm{RR}=0.43,95 \% \mathrm{CI} 0.25$ to $0.75)$, response ( $R R=-0.47,95 \%$ CI 0.30 to 0.74 ) and mean difference for depression score as measured on the HRSD (mean difference $-5.97,95 \% \mathrm{CI}-9.14$ to -2.80 , SMD $=-0.64,95 \%$ CI -1.00 to -0.29$)$. We included one trial of psychostimulants for people with $\mathrm{HIV}^{75}$ that lasted 2 weeks. There was a small

\begin{tabular}{|c|c|c|c|c|c|}
\hline \multirow[b]{2}{*}{ Outcomes } & \multirow{2}{*}{$\begin{array}{l}\text { Participants (studies), } \\
n\end{array}$} & \multirow{2}{*}{$\begin{array}{l}\text { Quality of the } \\
\text { evidence, GRADE }\end{array}$} & \multicolumn{2}{|c|}{ Effect size } & \multirow[b]{2}{*}{$95 \% \mathrm{Cl}$} \\
\hline & & & SMD & $\mathrm{RR}$ & \\
\hline \multicolumn{6}{|l|}{ Depression } \\
\hline Continuous measures: observer rated & $324(8)$ & Moderate $^{a}$ & -0.70 & & -0.97 to -0.43 \\
\hline Non-response ( $<50 \%$ improvement): observer rated & $224(5)$ & Moderate $^{a}$ & & 0.55 & 0.43 to 0.70 \\
\hline $\begin{array}{l}\text { Not achieving success/remission (reaching a specified cut- off): } \\
\text { patient rated }\end{array}$ & $75(2)$ & LOW $^{\mathrm{b}, \mathrm{c}}$ & & 0.70 & 0.40 to 1.25 \\
\hline \multicolumn{6}{|l|}{ Leaving the study early } \\
\hline Any reason & $302(6)$ & Moderate ${ }^{b}$ & & 1.23 & 0.81 to 1.88 \\
\hline As a result of adverse events & $239(5)$ & Moderate $^{b}$ & & 1.88 & 0.99 to 3.57 \\
\hline $\begin{array}{l}\text { SMD, standardised mean difference; RR, risk ratio. } \\
\text { a. Some studies not clear if they were double blinded. } \\
\text { b. } 95 \% \text { Cl compatible with benefit and no benefit. } \\
\text { c. Two small studies. }\end{array}$ & & & & & \\
\hline
\end{tabular}




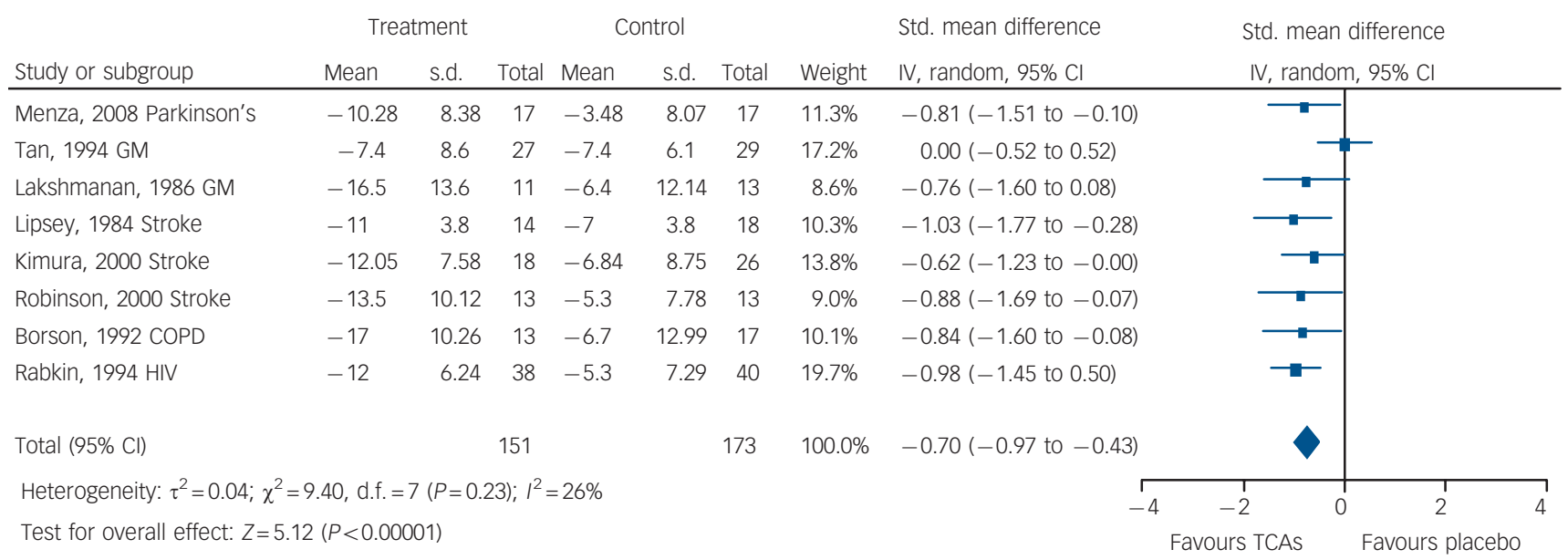

Fig. 3 Tricyclic antidepressants (TCAS) v. placebo: mean change in observer-rated depression rating scale score.

GM, general medical illness; COPD, chronic obstructive pulmonary disease; Std., standard; IV, inverse variance.

non-significant effect on depression $(\mathrm{SMD}=-0.36,95 \% \mathrm{CI}$ -1.20 to 0.49 ), but a large effect on fatigue ( $\mathrm{SMD}=-1.64$, $95 \%$ CI -2.64 to -0.65$)$.

\section{SSRIS $v$. TCAS}

We found 14 studies comparing TCAs and SSRIs. ${ }^{26,29,30,38,50,76-84}$ Four of these studies were not double blind..$^{29,76,82,83}$ Three of the studies examined the effect of antidepressants in depression in the context of Parkinson's disease, three in cancer and one each in epilepsy, HIV, stroke, cardiovascular disease, rheumatoid arthritis and 'vascular depression'. Table 3 and Figs 4 and 5 summarise the main outcomes of the analysis comparing SSRIs and TCAs.

Efficacy did not differ between the two groups of drugs (Fig. 5), with no statistically significant or clinically relevant differences observed on remission response or effect size (Table 3, top three rows)

There was a trend for SSRIs to be associated with better tolerability (Fig. 4). For example, people who received SSRIs were numerically less likely to leave the study early for any reason (Fig. 3) and numerically less likely to leave the study due to adverse events, but neither of these findings were statistically significant (Table 3, bottom two rows).

\section{Other head-to-head comparisons}

We found four head-to-head trials of comparisons other than SSRIs compared with TCAs. All but one ${ }^{85}$ were double-blind trials. All trials indicated little if any benefit of one drug or drug class over another. The trials covered a range of medical conditions including diabetes, ${ }^{86}$ epilepsy, ${ }^{87}$ stroke $^{85}$ and general medical illness, ${ }^{88}$ and included participants with both mild and moderate depression. One study comparing two different SSRIs ${ }^{86}$ $(n=23)$ did not indicate any benefit for either drug (fluoxetine and paroxetine) in terms of efficacy and tolerability, with no statistically significant differences observed on leaving the study early $(\mathrm{RR}=0.46,95 \% \mathrm{CI} 0.05$ to 4.38$)$, remission $(\mathrm{RR}=0.76$, $95 \%$ CI 0.32 to 1.80 ), response ( $\mathrm{RR}=1.15,95 \%$ CI 0.41 to 3.21 ) or effect size $(\mathrm{SMD}=0.00,95 \% \mathrm{CI}-0.88$ to 0.88$)$. Another comparing citalopram and venlafaxine ${ }^{85}(n=82)$ did not indicate any benefit for either drug. The outcomes for leaving the study early $(R R=0.69,95 \%$ CI $0.31-1.55)$, remission $(R R=0.90,95 \%$ CI $0.71-1.13)$ and response $(\mathrm{RR}=0.81,95 \%$ CI $0.50-1.13)$ were not statistically significantly different. Based on one small study ${ }^{87}$ $(n=42)$, there was no benefit in terms of efficacy for TCAs when compared with nomifensine, with response data indicating no statistically significant differences $(\mathrm{RR}=3.50,95 \%$ CI 0.89 13.78). One further study ${ }^{88}(n=48)$ compared maprotiline and mianserin but found no statistically significantly differences between the two. For example, results for leaving the study early $(\mathrm{RR}=0.58,95 \% \mathrm{CI} 0.22$ to 1.51$)$, response $(\mathrm{RR}=0.75(95 \% \mathrm{CI}$ 0.47 to 1.19 ) and effect size ( $\mathrm{SMD}=-0.47,95 \% \mathrm{CI}-1.15$ to 0.21 ) did not indicate that one drug was more efficacious than the other.

\section{Safety studies}

There were three studies that met the eligibility criteria of the review on the safety of antidepressants in chronic physical health

Table 3 Evidence summary of selective serotonin reuptake inhibitors $v$. tricyclic antidepressants

\begin{tabular}{|c|c|c|c|c|c|}
\hline \multirow[b]{2}{*}{ Outcomes } & \multirow{2}{*}{$\begin{array}{l}\text { Participants (studies), } \\
n\end{array}$} & \multirow{2}{*}{$\begin{array}{l}\text { Quality of the } \\
\text { evidence, GRADE }\end{array}$} & \multicolumn{2}{|c|}{ Effect size } & \multirow[b]{2}{*}{$95 \% \mathrm{Cl}$} \\
\hline & & & SMD & RR & \\
\hline \multicolumn{6}{|l|}{ Depression } \\
\hline Continuous measures: observer rated & $471(9)$ & Moderate ${ }^{a, b}$ & 0.14 & & -0.12 to 0.41 \\
\hline Remission (below cut-off): observer rated & $170(5)$ & Moderate $^{a}$ & & 1.11 & 0.83 to 1.48 \\
\hline Non-response ( $<50 \%$ reduction): observer rated & $625(8)$ & Moderate $^{a}$ & & 1.00 & 0.83 to 1.21 \\
\hline \multicolumn{6}{|l|}{ Leaving the study early } \\
\hline Any reason & $699(10)$ & Moderate ${ }^{a}$ & & 0.80 & 0.56 to 1.14 \\
\hline As a result of adverse events & $441(8)$ & Moderate $^{a}$ & & 0.90 & 0.54 to 1.51 \\
\hline $\begin{array}{l}\text { SMD, standardised mean difference; RR, risk ratio. } \\
\text { a. } 95 \% \mathrm{Cl} \text { compatible with benefit and no benefit. } \\
\text { b. Visual inspection suggests important heterogeneity. }\end{array}$ & & & & & \\
\hline
\end{tabular}




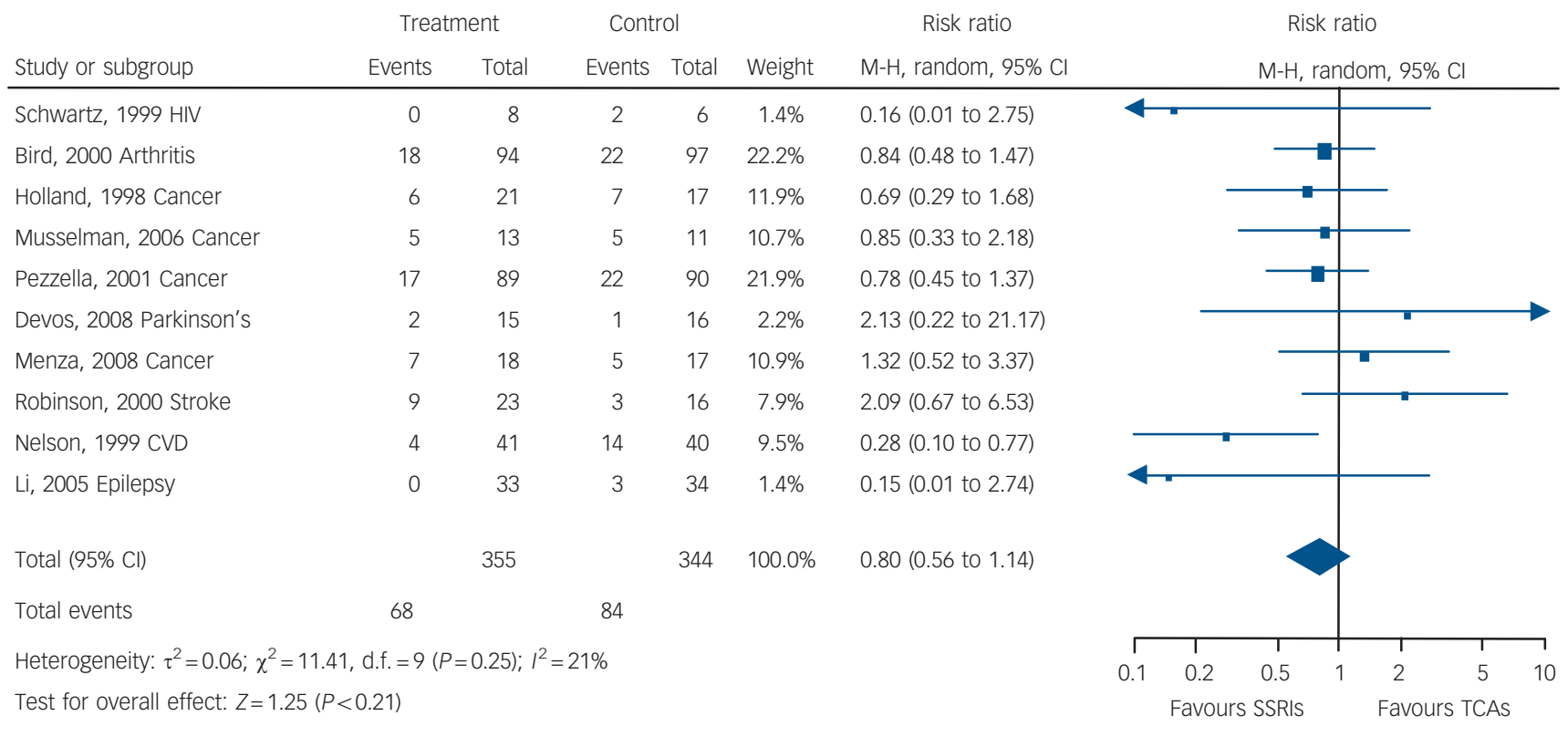

Fig. 4 Selective serotonin reuptake inhibitors (SSRIS) v. tricyclic antidepressants (TCAS): leaving the study for any reason.

CVD, cardiovascular disease.

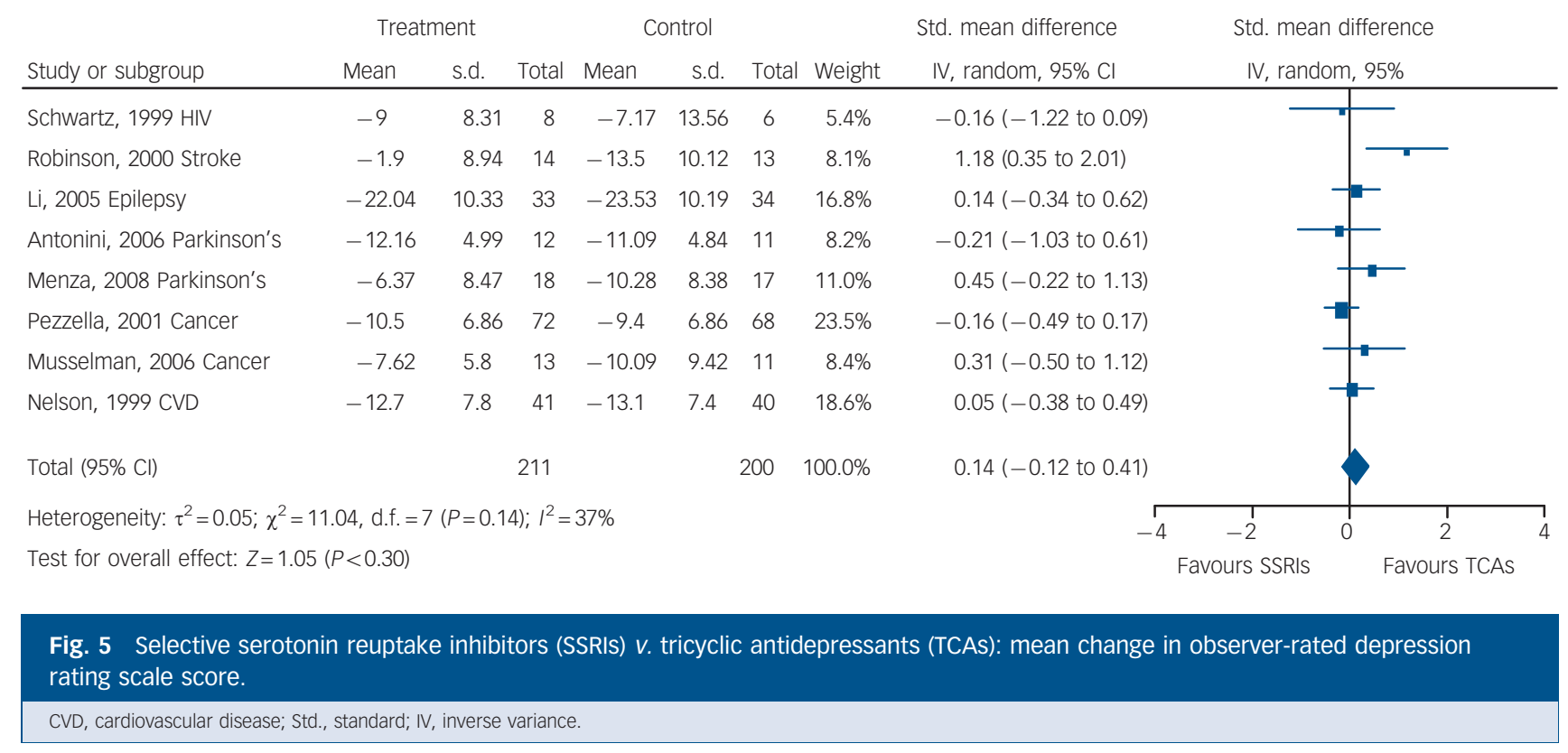

problems. Each addressed the use of antidepressants after myocardial infarction.

\section{MIND-IT (Myocardial Infarction and Depression}

- Intervention Trial)

This study focused on the safety of antidepressants in people who had a myocardial infarction and within this study a nested RCT was conducted comparing mirtazapine and placebo (which is included in the meta-analysis described earlier). ${ }^{71}$ Details are given in Table 4. It was observed ${ }^{89}$ that antidepressant use did not affect remission or cardiac event rate. In a follow-up subanalysis, response to mirtazapine seemed to predict lower risk of cardiac events $(7.4 \%$ over 18 months $)$ than both absence of pharmacological treatment (control group; event rate 11.2\%) and failure of pharmacological treatment (event rate 25.6\%). ${ }^{90}$

\section{ENRICHD (Enhancing Recovery in Coronary Heart Disease)}

This US study looked at people who had experienced a myocardial infarction. It mainly consisted of participants who had a relatively recent myocardial infarction (median 6 days), as compared with a minimum period of 3 months post-myocardial infarction for MIND-IT. In a paper concerned with outcomes relating to antidepressant use, ${ }^{91}$ it was reported that there was high usage of antidepressants (mainly SSRIs) in both treatment (baseline 9.1\%, 6 months $20.5 \%$, end of follow-up 28\%) and usual care (baseline 3.8\%, 6 months 9.4\%, end of follow-up 20.6\%) groups 


\begin{tabular}{|c|c|c|c|c|c|}
\hline Study & Design & Intervention $(n)$ & Control $(n)$ & Participants (n) & Outcome \\
\hline MIND-IT ${ }^{89}$ & $\begin{array}{l}\text { Double-blind comparison } \\
\text { of antidepressant } v \text {. } \\
\text { care as usual }\end{array}$ & $\begin{array}{l}\text { Mirtazapine (47) followed } \\
\text { by citalopram (15) if no } \\
\text { response or placebo (44) } \\
\text { followed by citalopram ( } 23 \text { ) } \\
\text { if no response ( } n=91 \text {, in total) }\end{array}$ & $\begin{array}{l}\text { Usual care (122) } \\
\text { (20 received } \\
\text { antidepressants) }\end{array}$ & $\begin{array}{l}\text { Participants with } \\
\text { depression after } \\
\text { Ml } \\
(n=213)\end{array}$ & $\begin{array}{l}\text { Non-remission: } 30.5 \% \text { intervention, } \\
32.1 \% \text { control }(\mathrm{OR}=0.93, \\
95 \% \mathrm{Cl} 0.53-1.63) \\
\text { Cardiac events: } 14 \% \text { intervention, } \\
13 \% \text { control } \\
\text { Use of antidepressant not associated } \\
\text { with altered rate of cardiac events } \\
(\mathrm{OR}=0.84,95 \% \mathrm{Cl} 0.38-1.84)\end{array}$ \\
\hline ENRICHD ${ }^{91}$ & $\begin{array}{l}\text { Secondary comparison of } \\
\text { outcomes in participants } \\
\text { receiving antidepressants }\end{array}$ & $\begin{array}{l}\text { Antidepressant use (initially } \\
\text { sertraline) }(n=446)\end{array}$ & $\begin{array}{l}\text { No antidepressant } \\
\text { use }(n=1388)\end{array}$ & $\begin{array}{l}\text { Participants with } \\
\text { depression after } \\
\text { Ml } \\
(n=1834)\end{array}$ & $\begin{array}{l}\text { All cause mortality: adjusted mortality } \\
0.63(95 \% \mathrm{Cl} 0.43-0.93) \\
\text { Recurrent } \mathrm{Ml} \text { : adjusted mortality } 0.57 \\
(95 \% \mathrm{Cl} 0.38-0.87) \\
\text { Use of antidepressants reduced } \\
\text { mortality and recurrence of } \mathrm{Ml}\end{array}$ \\
\hline SADHART $^{36}$ & $\begin{array}{l}\text { Randomised double-blind } \\
\text { placebo-controlled } \\
\text { comparison of sertraline } \\
\text { and placebo }\end{array}$ & $\begin{array}{l}\text { Sertraline } 50-200 \mathrm{mg} \text { day } \\
\text { for } 24 \text { weeks }(n=186)\end{array}$ & $\begin{array}{l}\text { Placebo for } \\
24 \text { weeks } \\
(n=183)\end{array}$ & $\begin{array}{l}\text { Participants with } \\
\text { depression } \\
\text { post-Ml (74\%) or } \\
\text { unstable angina } \\
(26 \%) \\
(n=369)\end{array}$ & $\begin{array}{l}\text { Response rates: } 67 \% \text { sertraline, } \\
53 \% \text { placebo ( } P=0.01) \\
\text { Severe cardiovascular adverse } \\
\text { events: } 14.5 \% \text { sertraline, } 22.4 \% \\
\text { placebo (NS) } \\
\text { Sertraline no different from placebo } \\
\text { on measures of left ventricular } \\
\text { ejection fraction, QTc prolongation } \\
\text { and other measures of cardiovascular } \\
\text { function or mortality }\end{array}$ \\
\hline
\end{tabular}

(Table 4). For the primary outcome of the study, death or non-fatal myocardial infarction, there was a reduced risk for those taking antidepressants, particularly SSRIs. ${ }^{92}$

\section{SADHART (Sertraline Antidepressant Heart Attack Randomized Trial)}

This trial ${ }^{36}$ included 369 patients with an acute myocardial infarction or unstable angina and comorbid major depressive disorder. (The data on the efficacy of sertraline for depression symptoms were included in the meta-analysis described earlier.) Sertraline appeared neither to increase nor decrease cardiovascular risks or mortality but was more effective than placebo in treating depression (Table 4).

\section{Discussion}

\section{Main findings}

In this systematic review we have examined the key outcomes of 63 randomised controlled trials (5794 participants) of antidepressants in a range of chronic physical conditions. Antidepressants of all types appear to be effective in depression in the context of chronic physical conditions but no particular drug or group of drugs was shown to have clear superiority in respect to efficacy or tolerability. Antidepressants of all groups were less well tolerated than placebo (although with TCAs this did not reach statistical significance). Only SSRIs were observed to improve quality of life measures; data were insufficient to draw conclusions about other antidepressants.

The effect size calculated here for antidepressants in depression occurring in the context of physical illness is broadly similar to that seen in depression not associated with physical illness: usually between 0.2 and $0.6 .^{93}$ For SSRIs in physical illness, the effect size was shown to be around 0.3 (depending on the subanalysis conducted) and around 0.6 for TCAs. No inferences should be drawn from the numerical differences in effect size noted for different drugs because in all cases confidence intervals overlapped and moreover, each effect size was calculated from markedly different studies in different populations. Participants receiving either SSRIs or TCAs were more likely (around twice as likely) to leave studies early because of adverse effects. Notably, confidence intervals for TCAs did not exclude the possibility of their being no different from placebo, although with fewer studies involving TCAs, this may at least partly be a result of relatively lower statistical power compared with SSRIs. Data on other drugs were insufficient to draw conclusions in this regard.

Our results are similar to those of a recent Cochrane review of antidepressants in physically ill people. ${ }^{94}$ Using somewhat different search criteria, this review included 44 placebo-controlled studies involving 3372 participants ( 25 studies and 1674 participants in the efficacy analysis). Antidepressants, as a group, were found to be more efficacious than placebo (response: odds ratio $(\mathrm{OR})=2.33$, 95\% CI 1.80-3.00). The SSRIs, but not the TCAs, were associated with a statistically significant increased risk of withdrawal from trials (at 6-8 weeks, for SSRIs OR $=1.43,95 \%$ CI 1.04-1.96; TCAs OR $=1.69,95 \%$ CI 0.98-2.92).

Overall, no particular drug can be recommended in any particular physical condition based on data reviewed here or in the above mentioned Cochrane review. ${ }^{94}$ Nonetheless, SSRIs may be seen as drugs of choice in people with chronic physical health problems assuming interactions and contraindications do not preclude their use. Choice of SSRI may be influenced by findings of a matrix meta-analysis in people without physical health problems that suggested that sertraline and escitalopram had advantages in respect to efficacy and acceptability, ${ }^{95}$ with sertraline recommended as a first-choice drug.

Sertraline, mirtazapine and possibly other SSRIs (such as citalopram) appear to be safe post-myocardial infarction (when considering safety outcomes from effectiveness studies included). The advantages of effectiveness studies are, first, that sample sizes tend to be larger and provide longer follow-up than efficacy studies in this area. Second, effectiveness trials seek to minimise differences between study conditions and routine clinical practice and so such findings are more readily applicable to clinical practice. Therefore it is important to compare the results found 
in these trials with the efficacy trials reviewed above to assess whether they confirm conclusions of the efficacy studies and/or provide additional data not usually reported in other trials. However, it should also be noted there are clear disadvantages in that given the complexity and the reduced level of control usually associated with these studies, it is often difficult to draw firm conclusions on causality. What is clear from these effectiveness studies is that mirtazapine, sertraline and citalopram have, at worst, no deleterious effect on cardiac outcome following myocardial infarction. This is a finding in accord with other safety studies. ${ }^{34,96}$ What is less clear is the effect of antidepressants on depression post-myocardial infarction. By no means all studies show a clear advantage for antidepressants over placebo or control in depression post-myocardial infarction (for example, MIND-IT ${ }^{71}$ found no advantage for antidepressants over control - this is usually explained by the ephemeral nature of depression after myocardial infarction). However, the possibility that antidepressants might improve mortality post-myocardial infarction and that this may be related to their efficacy in depression should encourage their use. Depression post-myocardial infarction increases mortality by up to sixfold, ${ }^{13,97,98}$ so any positive effects of treatment on mortality are to be welcomed.

\section{Strengths and limitations}

There are three important limitations to the present analysis. First, study quality tended to be rated as low or moderate, largely because authors often failed to describe methods of randomisation or efficacy of masking. An important number of studies were not double blind in design. Most studies included only small numbers of participants (usually around 20-60, although there were a handful of much larger studies). Second, the method of analysis - the grouping of drugs by drug class - is open to censure. We could have analysed by individual physical condition and examined the effect of (perhaps all) antidepressants in, say, depression occurring in the context of epilepsy or multiple sclerosis. However, there was a considerable disparity in the number of studies conducted and number of participants included in different physical conditions and so statistical power is likely to have varied considerably. We might then have concluded that antidepressants were effective in treating depression occurring in the context of certain physical conditions but not others. Apparent lack of effect may have then been a result of low statistical power rather than the absence of efficacy. Third, we were unable to determine outcomes for quality of life and physical outcomes for most drug groups. Of 36 studies comparing SSRIs with placebo, 7 included quality-of-life measures and for SSRIs a clear advantage was shown over placebo. For other drugs, too few individual studies included these outcomes for us to make a clear evaluation of their effects.

Advantages of our method include a rigorous and clearly described search technique and quality assessment that uncovered a large number of studies published. Combining study outcomes by meta-analysis allowed us to see clear benefits for drugs or drug groups for which the findings of most individual trials were equivocal. For example, only 6 of 25 trials comparing SSRIs with placebo clearly favoured the SSRI being studied (that is, showed statistically significant advantages). Our meta-analysis of these studies showed a clear efficacy advantage for SSRIs on a range of outcomes.

\section{Clinical implications}

Antidepressants appear to be effective but relatively poorly tolerated in the treatment of depression occurring in the context of chronic physical illness. No particular drug or drug group is preferred, although SSRIs may be better tolerated than TCAs and have a clear benefit on quality of life. The SSRIs may also be less likely than TCAs to be involved in pharmacodynamic interactions because they largely lack sedative, antimuscarinic and arrhythmogenic properties. The use of SSRIs (such as sertraline and citalopram) and mirtazapine is safe post-myocardial infarction and may confer benefits on cardiac mortality. Despite clinical concerns over adverse effects and drug interactions, antidepressants should not be withheld in the treatment of depression associated with chronic physical illness.

David Taylor, PhD, Pharmacy Department, South London and Maudsley NHS Foundation Trust, and the Pharmaceutical Sciences Division, King's College London; Nicholas Meader, PhD, Victoria Bird, BSC, National Collaborating Centre for Menta Health, Royal College of Psychiatrists, and the Centre for Outcomes Research and Effectiveness, University College London; Steve Pilling, PhD, Centre for Outcomes Research and Effectiveness, University College London, and Camden and Islington NHS Foundation Trust, London; Francis Creed, FmedSci, Psychiatry Research Group, University of Manchester; David Goldberg, DM, Institute of Psychiatry, King's College London, UK

Correspondence: David Taylor, Pharmacy Department, Maudsley Hospital, Denmark Hill, London SE5 8AZ, UK. Email: David.Taylor@slam.nhs.uk

First received 13 Jan 2010, final revision 8 Jul 2010, accepted 15 Sep 2010

\section{References}

1 Prince M, Patel V, Saxena S, Maj M, Maselko J, Phillips MR, et al. No health without mental health. Lancet 2007; 370: 859-77.

2 Egede LE. Major depression in individuals with chronic medical disorders: prevalence, correlates and association with health resource utilization, lost productivity and functional disability. Gen Hosp Psychiatry 2007; 29: 409-16.

3 Lin EH, Korff MV, Alonso J, Angermeyer MC, Anthony J, Bromet E, et al. Mental disorders among persons with diabetes-results from the World Mental Health Surveys. J Psychosom Res 2008; 65: 571-80.

4 Wilhelm K, Mitchell P, Slade T, Brownhill S, Andrews G. Prevalence and correlates of DSM-IV major depression in an Australian national survey. $J$ Affect Disord 2003; 75: 155-62.

5 Patten SB, Beck CA, Williams JV, Barbui C, Metz LM. Major depression in multiple sclerosis: a population-based perspective. Neurology 2003; 61: $1524-7$

6 Patten SB, Beck CA, Kassam A, Williams JV, Barbui C, Metz LM. Long-term medical conditions and major depression: strength of association for specific conditions in the general population. Can J Psychiatry 2005; 50: 195-202.

7 Scott KM, McGee MA, Wells JE, Oakley Browne MA. Obesity and mental disorders in the adult general population. J Psychosom Res 2008; 64: 97-105.

8 Moussavi S, Chatterji S, Verdes E, Tandon A, Patel V, Ustun B. Depression, chronic diseases, and decrements in health: results from the World Health Surveys. Lancet 2007; 370: 851-8.

9 Ismail K, Winkley K, Stahl D, Chalder T, Edmonds M. A cohort study of people with diabetes and their first foot ulcer. Diabetes Care 2007; 30: 1473-9.

10 Tseng $\mathrm{CH}$. Mortality and causes of death in a national sample of diabetic patients in Taiwan. Diabetes Care 2005; 28: 1267-8.

11 Von Korff M, Katon W, Lin EH, Simon G, Ludman E, Oliver M, et al. Potentially modifiable factors associated with disability among people with diabetes. Psychosom Med 2005; 67: 233-40.

12 Taylor D. Antidepressant drugs and cardiovascular pathology: a clinical overview of effectiveness and safety. Acta Psychiatr Scand 2008; 118: 434-42.

13 Frasure-Smith N, Lesperance F, Talajic M. Depression and 18-month prognosis after myocardial infarction. Circulation 1995; 91: 999-1005.

14 Frasure-Smith N, Lesperance F. Depression - a cardiac risk factor in search of a treatment. JAMA 2003; 289: 3171-3.

15 Allebeck $P$, Bolund C, Ringback G. Increased suicide rate in cancer patients. A cohort study based on the Swedish Cancer-Environment Register. J Clin Epidemiol 1989; 42: 611-6.

16 Christensen J, Vestergaard M, Mortensen PB, Sidenius P, Agerbo E. Epilepsy and risk of suicide: a population-based case-control study. Lancet Neurol 2007; 6: 693-8.

17 DiMatteo MR, Lepper HS, Croghan TW. Depression is a risk factor for noncompliance with medical treatment: meta-analysis of the effects of 
anxiety and depression on patient adherence. Arch Intern Med 2000; 160: 2101-7

18 National Institute for Health and Clinical Excellence. The Treatment and Management of Depression in Adults with Chronic Physical Health Problems (partial update of CG23). NICE, 2009 (http://guidance.nice.org.uk/ CG/WaveR/23)

19 Scottish Intercollegiate Guidelines Network (SIGN). Methodology checklist 2 randomised controlled trials. In SIGN 50: A Guidelines Developer's Handbook: 56-60. SIGN, 2008.

20 Guyatt GH, Oxman AD, Vist GE, Kunz R, Falck-Ytter $Y$, onso-Coello $P$, et al. GRADE: an emerging consensus on rating quality of evidence and strength of recommendations. BMJ 2008; 336: 924-6.

21 Hamilton M. A rating scale for depression. J Neurol Neurosurg Psychiatry 1960; 23: 56-62.

22 Beck AT, Beamesderfer A. Assessment of depression: the depression inventory. Mod Probl Pharmacopsychiatry 1974; 7: 151-69.

23 International Quality of Life Assessment (IQOLA) Project. SF-36 Health Survey. 2009

24 Cochrane IMS. Review Manager 5. Cochrane IMS, 2009 (http:// ims.cochrane.org/)

25 Egger M, Smith GD, Schneider M, Minder C. Bias in meta-analysis detected by a simple, graphical test. BMJ 1997; 315: 629-34.

26 Musselman DL, Somerset WI, Guo Y, Manatunga AK, Porter M, Penna S, et al. A double-blind, multicenter, parallel-group study of paroxetine, desipramine, or placebo in breast cancer patients (stages I, II, III, and IV) with major depression. J Clin Psychiatry 2006; 67: 288-96.

27 Razavi D, Alliaire JF, Smith M, Salimpour A, Verra M, Desclaux B, et al. The effect of fluoxetine on anxiety and depression symptoms in cancer patients. Acta Psychiatr Scand 1996; 94: 205-10.

28 Murray V, von AM, Bartfai A, Berggren AL, Landtblom AM, Lundmark J, et al. Double-blind comparison of sertraline and placebo in stroke patients with minor depression and less severe major depression. J Clin Psychiatry 2005 66: 708-16.

29 Chen W, Wang GF, Chen XH, Sheng YL, Zhu H. Effects of paroxetine on function recovery in patients with poststroke depression. Chin J Clin Rehab 2002; 6: 2014-5.

30 Robinson RG, Schultz SK, Castillo C, Kopel T, Kosier JT, Newman RM, et al. Nortriptyline versus fluoxetine in the treatment of depression and in short-term recovery after stroke: a placebo-controlled, double-blind study. Am J Psychiatry 2000; 157: 351-9.

31 Fruehwald S, Gatterbauer E, Rehak P, Baumhackl U. Early fluoxetine treatment of post-stroke depression - a three-month double-blind placebocontrolled study with an open-label long-term follow up. J Neurol 2003; 250 347-51.

32 Anderson IM, Tomenson BM. The efficacy of selective serotonin re-uptake inhibitors in depression: a meta-analysis of studies against tricyclic antidepressants. J Psychopharmacol 1994; 8: 238-49.

33 Wiart L, Petit H, Joseph PA, Mazaux JM, Barat M. Fluoxetine in early poststroke depression: a double-blind placebo-controlled study. Stroke 2000 31: 1829-32.

34 Strik JJ, Honig A, Lousberg R, Lousberg AH, Cheriex EC, Tuynman-Qua HG, et al. Efficacy and safety of fluoxetine in the treatment of patients with major depression after first myocardial infarction: findings from a double-blind placebo-controlled trial. Psychosom Med 2000; 62: 783-9.

35 Lesperance F, Frasure-Smith N, Koszycki D, Laliberte MA, van ZyI LT, Baker B et al. Effects of citalopram and interpersonal psychotherapy on depression in patients with coronary artery disease: the Canadian Cardiac Randomized Evaluation of Antidepressant and Psychotherapy Efficacy (CREATE) trial. JAMA 2007; 297: 367-79.

36 Glassman AH, O'Connor CM, Califf RM, Swedberg K, Schwartz P, Bigger Jr JT, et al. Sertraline treatment of major depression in patients with acute $\mathrm{Ml}$ or unstable angina. JAMA 2002; 288: 701-9.

37 Ehde DM, Kraft GH, Chwastiak L, Sullivan MD, Gibbons LE, Bombardier $\mathrm{CH}$, et al. Efficacy of paroxetine in treating major depressive disorder in persons with multiple sclerosis. Gen Hosp Psychiatry 2008; 30: 40-8.

38 Menza M, Fronzo Dobkin R, Marin H, Mark MH, Gara M, Buyske S, et al. A controlled trial of antidepressants in patients with Parkinson disease and depression. Neurology 2008; 72: 886-92.

39 wermuth L, Sorensen P, Timm S, Christensen B, Utzon NP, Boas J, et al. Depression in idiopathic Parkinson's disease treated with citalopram: a placebo-controlled trial. Nord J Psychiatry 1998; 52: 163-9.

40 Mauri MC, Ferrara A, Fabiano L, Ricci C, Invernizzi G. A double blind study on fluvoxamine vs. placebo in depressed HIV positive patients: short-term and perspective results. Inter Psych 1994; 10: 199-201.
41 Rabkin JG, Wagner GJ, Rabkin R. Fluoxetine treatment for depression in patients with HIV and AIDS: a randomized, placebo-controlled trial. Am J Psychiatry 1999; 156: 101-7.

42 Tollefson GD, Holman SL. Analysis of the Hamilton Depression Rating Scale factors from a double-blind, placebo-controlled trial of fluoxetine in geriatric major depression. Int Clin Psychopharmacol 1993; 8: 253-9.

43 Forest Research Institute. A Double-Blind, Flexible Dose Comparison of the Safety and Efficacy of Escitalopram and Placebo in the Treatment of Major Depressive Disorder in Diabetic Patients. Lundbeck, 2007.

44 Lustman PJ, Freedland KE, Griffith LS, Clouse RE. Fluoxetine for depression in diabetes: a randomized double-blind placebo-controlled trial. Diabetes Care 2000; 23: 618-23.

45 Paile-Hyvarinen M, Wahlbeck K, Eriksson JG. Quality of life and metabolic status in mildly depressed women with type 2 diabetes treated with paroxetine: a single-blind randomised placebo controlled trial. BMC Fam Pract 2003; 4: 7

46 Eiser N, Harte R, Spiros K, Phillips C, Isaac MT. Effect of treating depression on quality-of-life and exercise tolerance in severe COPD. COPD 2005; 2 : 233-41.

47 Brown ES, Vigil L, Khan DA, Liggin JD, Carmody TJ, Rush AJ. A randomized trial of citalopram versus placebo in outpatients with asthma and major depressive disorder: a proof of concept study. Biol Psychiatry 2005; 58: 865-70.

48 Blumenfield M, Levy NB, Spinowitz B, Charytan C, Beasley Jr CM, Dubey AK, et al. Fluoxetine in depressed patients on dialysis. Int J Psychiatry Med 1997; 27: $71-80$.

49 Evans M, Hammond M, Wilson K, Lye M, Copeland J. Placebo-controlled treatment trial of depression in elderly physically ill patients. Int J Geriatr Psychiatry 1997; 12: 817-24.

50 Devos D, Dujardin K, Poirot I, Moreau C, Cottencin O, Thomas P, et al. Comparison of desipramine and citalopram treatments for depression in Parkinson's disease: a double-blind, randomized, placebo-controlled study. Mov Disord 2008; 23: 850-7.

51 Leentjens AF, Vreeling FW, Luijckx GJ, Verhey FR. SSRIs in the treatment of depression in Parkinson's disease. Int J Geriatr Psychiatry 2003; 18: 552-4.

52 Rabkin JG, Wagner GJ, McElhiney MC, Rabkin R, Lin SH. Testosterone versus fluoxetine for depression and fatigue in HIV/AIDS: a placebo-controlled trial. J Clin Psychopharmacol 2004; 24: 379-85.

53 Yang J, Zhao Y, Bai S. Controlled study on antidepressants treatment of patient with post-stroke depression. Chin J Ment Health 2002; 16: 871-2.

54 Gottlieb SS, Kop WJ, Thomas SA, Katzen S, Vesely MR, Greenberg N, et al. A double-blind placebo-controlled pilot study of controlled-release paroxetine on depression and quality of life in chronic heart failure. Am Heart J 2007; 153: 868-73.

55 Fisch MJ, Loehrer PJ, Kristeller J, Passik S, Jung SH, Shen J, et al. Fluoxetine versus placebo in advanced cancer outpatients: a double-blinded trial of the Hoosier Oncology Group. J Clin Oncol 2003; 21: 1937-43.

56 Lacasse $Y$, Beaudoin L, Rousseau L, Maltais F. Randomized trial of paroxetine in end-stage COPD. Monaldi Arch Chest Dis 2004; 61: 140-7.

57 Morrow GR, Hickok JT, Roscoe JA, Raubertas RF, Andrews PL, Flynn PJ, et al. Differential effects of paroxetine on fatigue and depression: a randomized, double-blind trial from the University of Rochester Cancer Center Community Clinical Oncology Program. J Clin Oncol 2003; 21: 4635-41.

58 Paile-Hyvarinen M, Wahlbeck K, Eriksson JG. Quality of life and metabolic status in mildly depressed patients with type 2 diabetes treated with paroxetine: a double-blind randomised placebo controlled 6-month trial. BMC Fam Pract 2007; 8: 34.

59 Lustman PJ, Clouse RE, Nix BD, Freedland KE, Rubin EH, McGill JB, et al. Sertraline for prevention of depression recurrence in diabetes mellitus: a randomized, double-blind, placebo-controlled trial. Arch Gen Psychiatry 2006; 63: 521-9.

60 McFarlane A, Kamath MV, Fallen EL, Malcolm V, Cherian F, Norman G. Effect of sertraline on the recovery rate of cardiac autonomic function in depressed patients after acute myocardial infarction. Am Heart J 2001; 142: 617-23.

61 Small GW, Birkett M, Meyers BS, Koran LM, Bystritsky A, Nemeroff CB. Impact of physical illness on quality of life and antidepressant response in geriatric major depression. Fluoxetine Collaborative Study Group. J Am Geriatr Soc 1996; 44: 1220-5.

62 Andersen J, Aabro E, Gulmann N, Hjelmsted A, Pedersen HE. Anti-depressive treatment in Parkinson's disease. A controlled trial of the effect of nortriptyline in patients with Parkinson's disease treated with L-DOPA. Acta Neurol Scand 1980; 62: 210-9.

63 Borson S, McDonald GJ, Gayle T, Deffebach M, Lakshminarayan S, VanTuinen C. Improvement in mood, physical symptoms, and function with nortriptyline for depression in patients with chronic obstructive pulmonary disease. Psychosomatics 1992; 33: 190-201. 
64 Kimura M, Robinson RG, Kosier JT. Treatment of cognitive impairment after poststroke depression: a double-blind treatment trial. Stroke 2000; 31: 1482-6.

65 Lakshmanan M, Mion LC, Frengley JD. Effective low dose tricyclic antidepressant treatment for depressed geriatric rehabilitation patients. A double-blind study. J Am Geriatr SOC 1986; 34: 421-6.

66 Lipsey JR, Robinson RG, Pearlson GD, Rao K, Price TR. Nortriptyline treatment of post-stroke depression: a double-blind study. Lancet 1984; 1: 297-300.

67 Lustman PJ, Griffith LS, Clouse RE, Freedland KE, Eisen SA, Rubin EH, et al. Effects of nortriptyline on depression and glycemic control in diabetes: results of a double-blind, placebo-controlled trial. Psychosom Med 1997; 59 241-50

68 Rabkin JG, Rabkin R, Harrison W, Wagner G. Effect of imipramine on mood and enumerative measures of immune status in depressed patients with HIV illness. Am J Psychiatry 1994; 151: 516-23.

69 Tan RS, Barlow RJ, Abel C, Reddy S, Palmer AJ, Fletcher AE, et al. The effect of low dose lofepramine in depressed elderly patients in general medica wards. Br J Clin Pharmacol 1994; 37: 321-4.

70 Raffaele R, Rampello L, Vecchio I, Tornali C, Malaguarnera M. Trazodone therapy of the post-stroke depression. Arch Gerontol Geriatr 1996; 22 (suppl 1): 217-20.

71 van den Brink RH, van Melle JP, Honig A, Schene AH, Crijns HJ, Lambert FP, et al. Treatment of depression after myocardial infarction and the effects on cardiac prognosis and quality of life: rationale and outline of the Myocardia INfarction and Depression-Intervention Trial (MIND-IT). Am Heart J 2002; 144: $219-25$

72 Wise TN, Wiltse CG, Iosifescu DV, Sheridan M, Xu JY, Raskin J. The safety and tolerability of duloxetine in depressed elderly patients with and without medical comorbidity. Int J Clin Pract 2007; 61: 1283-93.

73 Costa D, Mogos I, Toma T. Efficacy and safety of mianserin in the treatment of depression of women with cancer. Acta Psychiatr Scand Suppl 1985; $\mathbf{3 2 0}$ 85-92.

74 van Heeringen $\mathrm{K}$, Zivkov M. Pharmacological treatment of depression in cancer patients. A placebo-controlled study of mianserin. Br J Psychiatry 1996: 169: 440-3

75 Wagner GJ, Rabkin R. Effects of dextroamphetamine on depression and fatigue in men with HIV: a double-blind, placebo-controlled trial. J Clin Psychiatry 2000; 61: 436-40.

$76 \mathrm{Li}$ W, Ma DR. A randomized controlled trial to evaluate the efficacy of paroxetine and doxepin in treating epileptic patients with depression. Zhong Linch Kangfu 2005; 9: 20-1

77 Holland JC, Romano SJ, Heiligenstein JH, Tepner RG, Wilson MG. A controlled trial of fluoxetine and desipramine in depressed women with advanced cancer. Psychooncology 1998; 7: 291-300.

78 Pezzella G, Moslinger-Gehmayr R, Contu A. Treatment of depression in patients with breast cancer: a comparison between paroxetine and amitriptyline. Breast Cancer Res Treat 2001; 70: 1-10.

79 Schwartz JA, McDaniel JS. Double-blind comparison of fluoxetine and desipramine in the treatment of depressed women with advanced HIV disease: a pilot study. Depress Anxiety 1999; 9: 70-4

80 Nelson JC, Kennedy JS, Pollock BG, Laghrissi-Thode F, Narayan M, Nobler MS, et al. Treatment of major depression with nortriptyline and paroxetine in patients with ischemic heart disease. Am J Psychiatry 1999; 156: 1024-8.

81 Bird H, Broggini M. Paroxetine versus amitriptyline for treatment of depression associated with rheumatoid arthritis: a randomized, double blind, parallel group study. J Rheumatol 2000; 27: 2791-7.
82 Huang LL. Comparison of therapeutic effects and side effects between fluoxetine hydrochloride and clomipramine in patients with vascular depression. Zhong Linch Kangfu 2005; 9: 226-8.

83 Antonini A, Tesei S, Zecchinelli A, Barone P, De GD, Canesi M, et al. Randomized study of sertraline and low-dose amitriptyline in patients with Parkinson's disease and depression: effect on quality of life. Mov Disord 2006; 21: 1119-22.

84 Pollock BG, Laghrissi-Thode F, Wagner WR. Evaluation of platelet activation in depressed patients with ischemic heart disease after paroxetine or nortriptyline treatment. J Clin Psychopharmacol 2000; 20: 137-40.

85 Zhao CS, Puurunen K, Sivenius J, Jolkkonen J, Schallert T. Psychotropic medication and stroke outcome. Am J Psychiatry 2005; 162: 1026-7.

86 Gulseren L, Gulseren S, Hekimsoy Z, Mete L. Comparison of fluoxetine and paroxetine in type II diabetes mellitus patients. Arch Med Res 2005; 36 159-65.

87 Robertson MM, Trimble MR. The treatment of depression in patients with epilepsy. A double-blind trial. J Affect Disord 1985; 9: 127-36.

88 Schifano F, Garbin A, Renesto V, De Dominicis MG, Trinciarelli G, Silvestri A et al. A double-blind comparison of mianserin and maprotiline in depressed medically ill elderly people. Acta Psychiatr Scand 1990; 81: 289-94.

89 van Melle JP, de Jonge P, Honig A, Schene AH, Kuyper AMG, Crijns HJGM, et al. Effects of antidepressant treatment following myocardial infarction. Br J Psychiatry 2007; 190: 460-6.

90 de Jonge P, Honig A, van Melle JP, Schene AH, Kuyper AM, Tulner D, et al. Nonresponse to treatment for depression following myocardial infarction: association with subsequent cardiac events. Am J Psychiatry 2007; 164 $1371-8$.

91 Berkman LF, Blumenthal J, Burg M, Carney RM, Catellier D, Cowan MJ, et al. Effects of treating depression and low perceived social support on clinical events after myocardial infarction: the Enhancing Recovery in Coronary Heart Disease Patients (ENRICHD) Randomized Trial. JAMA 2003; 289: 3106-16.

92 Taylor CB, Youngblood ME, Catellier D, veith RC, Carney RM, Burg MM, et al. Effects of antidepressant medication on morbidity and mortality in depressed patients after myocardial infarction. Arch Gen Psychiatry 2005; 62: 792-8.

93 Turner EH, Matthews AM, Linardatos E, Tell RA, Rosenthal R. Selective publication of antidepressant trials and its influence on apparent efficacy. N Engl J Med 2008; 358: 252-60.

94 Rayner L, Price A, Evans A, Valsraj K, Higginson IJ, Hotopf M. Antidepressants for depression in physically ill people. Cochrane Database Syst Rev 2010; 3: CD007503.

95 Cipriani A, Furukawa TA, Salanti G, Geddes JR, Higgins JP, Churchill R, et al. Comparative efficacy and acceptability of 12 new-generation antidepressants: a multiple-treatments meta-analysis. Lancet 2009; 373 : 746-58.

96 Rigotti NA, Thorndike AN, Regan S, McKool K, Pasternak RC, Chang Y, et al. Bupropion for smokers hospitalized with acute cardiovascular disease. Am J Med 2006; 119: 1080-7.

97 Frasure-Smith N, Lesperance F, Juneau M, Talajic M, Bourassa MG. Gender, depression, and one-year prognosis after myocardial infarction. Psychosom Med 1999; 61: 26-37.

98 Frasure-Smith N, Lesperance F, Talajic M. Depression following myocardial infarction. Impact on 6-month survival. JAMA 1993; 270: 1819-25.

99 Rabkin JG, Wagner GJ, Rabkin R. Fluoxetine treatment for depression in patients with HIV and AIDS: a randomized, placebo-controlled trial. Am J Psychiatry 1999; 156: 101-7. 